Textbooks for teaching and learning a foreign English language: Do they really facilitate students' acquisition of English relative clauses?

\author{
Hua, Tzu-Ling \\ Ming Chuan University, Taiwan (tzuling0619@gmail.com)
}

Received: 3 May 2019

Available Online: 3 July 2019
Revised: 31 May 2019
DOI: $10.5861 /$ ijrsll.2019.4006

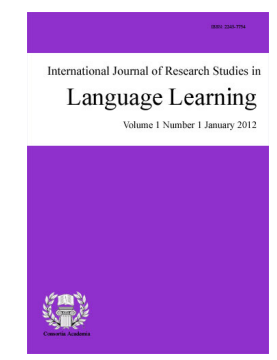

ISSN: 2243-7754 Online ISSN: 2243-7762

Accepted: 27 June 2019

OPEN ACCESS

\title{
Abstract
}

Textbooks play an important role in learners' language learning process. Yet, textbook writers may not be fully trained in the effective sequencing for grammatical structures. This study applies theoretical research to practical pedagogical considerations, and examines if current EFL textbooks in Taiwan facilitate students' acquisition of English relative clauses. Based on well-established hypotheses of the difficulty order for RC acquisition, thirty textbooks were examined. The results show that textbooks do not appear to be compatible with the current hypothesis of the acquisition of relative clauses in second language. The textbooks examined do not sequence relative clauses according to their complexity. Moreover, only a few types of relative clauses were presented. Classroom teachers who strictly adhere to such textbooks may result in the inhibition of the students' learning process, avoidance of relative clause use, and thus limitation of their language development. The findings of this study have implications for curriculum designers and English language educators as a reference for improving or modifying their pedagogical practice.

Keywords: second language acquisition; relative clauses; developmental sequences; textbook analysis; English language learning 


\section{Textbooks for teaching and learning a foreign English language: Do they really facilitate students' acquisition of English relative clauses?}

\section{Introduction}

Textbooks play an important role on learners' language learning process. Most of the time, teachers follow what is presented in the textbooks to teach, and students learn what they are taught. Yet, many L2 textbooks are written based on the writers' intuition, anecdotal evidence, and traditions (Ishihara \& Cohen, 2014). This may especially be the case for English grammar, as textbook writers may not be fully trained in the effective sequencing of grammatical structures. Since grammatical structures hold a central place in the language learning process (Ellis, 2006), it is important to understand L2 English grammar instruction in textbooks.

Previous research suggests that there is an order of difficulty in language acquisition, and that learners will benefit from being taught in line with this order (Cook, 2009; Ellis, 2005; Keßler, 2008). When learners are exposed to instruction in accordance with their L2 processing capacity, they not only produce the target language structures with a higher grammatical accuracy than those exposed to the reversed order, but their long-term acquisition of the structures is also enhanced (Mansouri \& Duffy, 2005). Whereas, when the instruction does not match the learner's developmental sequences, even when a specific structure is intensively drilled every day, leaners still face major difficulties (Felix, 1981). The underlying assumption is that learners are constrained by their language processing abilities, and learners must develop required procedural skills in a predetermined sequence over time (Pienemann, 1998). Accordingly, instruction is viewed as most beneficial if it comes at a point when the learner is developmentally ready (Pienemann, 1984).

Relative clauses (RCs) have been cited as one of the most difficult grammatical structures for English as a second language (ESL) learners to learn (Cho \& Lee, 2016). This is certainly the case for learners whose first language is Chinese (Chang, 2001). Evidence has shown that different types of RCs inherit different complexity levels, which are indicative of a universal ordering of difficulty for RC acquisition. The discovery of a universal order and sequence of SLA can and has helped to shape decisions on second language grammar teaching (Ellis, 2006), with crucial importance attached especially to the sequencing and timing of instruction (Doughty, 1991). Accordingly, the difficulty ordering for RC acquisition should be respected in the design of instructional materials.

Applying theoretical research to practical pedagogical considerations, the present study examined English RCs as presented for teaching EFL in textbooks for vocational high schools (VHSs) in Taiwan, with a special focus on whether these textbooks introduce RCs according to the hypothesized order of difficulty for RC acquisition. This examination can make English teachers aware of the strengths and weakness of instructional materials, and to what extent do they facilitate students' acquisition of English relative clauses.

\section{Literature review}

Three major hypotheses that predict an order of difficulty for RC acquisition are Keenan and Comrie's (1977) Noun Phrase Accessibility Hierarchy (NPAH), Kuno's (1974) Perceptual Difficulty Hypothesis (PDH), and Hamilton's (1994) SO Hierarchy Hypothesis (SOHH), as Izumi (2003) noted. NPAH examines the noun phrase position that can be relativized in the RC and forms an implicational hierarchy based on typological comparisons. The hierarchical ordering of the ease of accessibility, from most accessible for relativization to the least accessible in English is Subject (SU) > Direct Object (DO) $>$ Indirect Object (IO) $>$ Object of Preposition (OPREP) > Genitive (GEN) > Object of Comparison (OCOMP). (> means 'is more accessible than'). PDH looks at the location of the RC in the matrix sentence, that is, whether the RC is left, center, or right-embedded. It predicts that center embedding, which interrupts the processing of the matrix sentence with the $\mathrm{RC}$ is more 
Textbooks for foreign English language: Do they facilitate students' acquisition of English relative clauses?

difficult to process than right and left embedding.

While the above two hypotheses have been proposed with regard to difficulty order for RC acquisition, one discusses it only with respect to the RC itself and the other one discusses it with respect to the locations of the $\mathrm{RC}$ in the matrix sentence. Therefore, it is unclear what the difficulty order for the different types of RCs in the $\mathrm{RC}$ itself would be when we take their role in the matrix sentence into account. In order to determine the difficulty orders for English relativization for the present study, we apply the notion of processing difficulty proposed by Hamilton (1994) and the counting method he employed to determine the number of discontinuities in the structure as a predictor of difficulty and developmental order in RCs.

We first quantify the degrees of discontinuity in the various types of RCs in reference to the NPAH (see Appendix A). Note that in this study, we further distinguish the grammatical functions of the noun phrase in the $\mathrm{RC}$, particularly those which involve the genitive. The reason for this is made clear in the examples below:

I know the man who is a teacher.

I know the man whose wife is a teacher.

The relative pronoun 'who' in example (a) occurs in subject function in RC whereas in example (b), it is 'whose wife' (i.e. the genitive + a noun) that serves the subject function. In other words, the relative pronoun 'who' in example (a) is a subject itself but the genitive pronoun 'whose' in example (b) is a part of the relativization. Therefore, if we look at the genitive as a unit as 'whose+noun', the genitive can serve as, e.g. a subject, a direct object or indirect object, etc. in the RC. Accordingly, the genitive can be formed on noun phrases at any level of wh-extraction (Wolfe-Quintero, 1992), and can create a varying degree of phrasal discontinuity (See Appendix B). Therefore, if we characterize the grammatical function that RC constituent has, it can e.g. be a subject itself or be a subject containing the genitive pronoun. This tentative account for the functional role of the genitive in RCs explains the discrepancy of the genitive found in empirical studies on ESL RC acquisition (e.g. Gass, 1979; Hansen-Strain \& Strain, 1989).

Based on the processing discontinuity, the difficulty order for different RC types used for the purpose of the present study is illustrated in the scale 1 below. Note that in NPAH, relativization of indirect object is predicted to be more accessible than object of preposition, however, when we use the processing discontinuity to determine the difficulty order of RCs, these two types of RCs create the same number of discontinuities, and thus are assumed to have the same level of complexity. Empirical findings from studies on ESL RC acquisition lent support to this proposed difficulty order for English relativization. For example, it is found that there is a reverse relationship between IO and OOPREP type RCs, and IO type RCs are no easier than OOPREP type RCs (e.g. Pavesi, 1986; Hyltenstam, 1984).

In view of the empirical findings in support of the proposed difficulty order for different RCs types, scale 1, based on the processing discontinuity, is used for the present study.

Scale 1: Difficulty order for different RCs types used in the present study
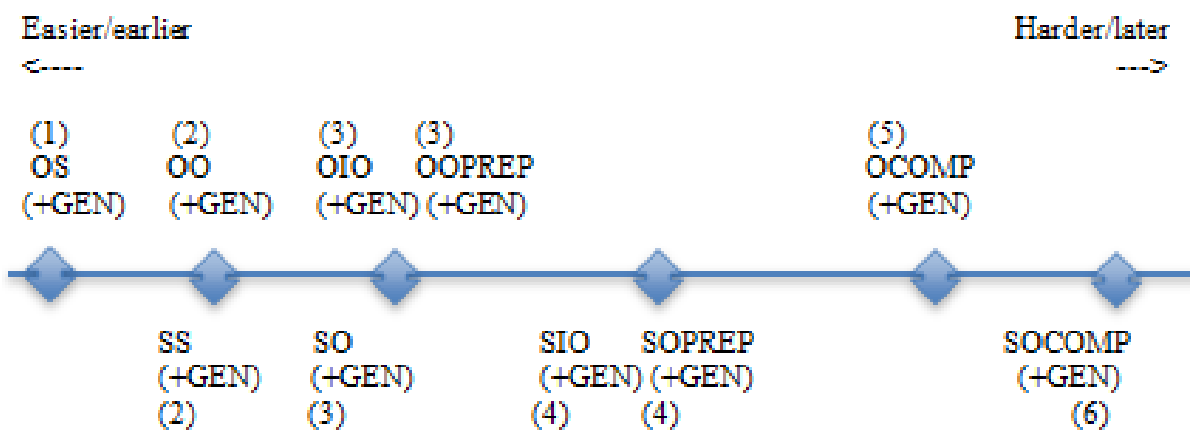

[Note. (1) the first code of each label refers to the function of the head noun of the matrix clause, and the second code refers to the role of the NP target of relativization in the $\mathrm{RC}$; (2) the number in bracket means the number of discontinuity created] 


\section{Research questions}

The research questions we seek to answer in this study are:

(1) What types of RCs are introduced in the textbooks?

(2) What is the order of RCs introduced in different textbooks?

(3) Do the textbooks introduce the RCs according to the hypothesised order of difficulty for RC acquisition?

\section{Methodology}

\subsection{Method}

Analyze English textbooks used by vocational high schools in Taiwan and compare their presentation with the difficulty ordering for different RCs types.

\subsection{Textbook range and selection}

High school education in Taiwan offers two tracks. One is academic track, and the other is vocational track. Each track is three years schooling, with two terms per year. The main difference between textbooks from these two tracks lies in the overall number of words introduced, with vocational track introducing fewer number of words than academic track (Everington, 2018). The Ministry of Education (MOE) in Taiwan evaluates textbooks proposed by different publishers based on national curriculum guidelines, and announces a list of approved textbooks from which each school can make their own choice of textbooks to use. Each version of textbook, approved by the Ministry of Education (MOE) in Taiwan to use in VHSs, is included in our analysis to provide a complete picture of how the RCs are introduced from each of the approved publishers. This gives us five different publishers according to the 2013 textbook approval list from the MOE. Therefore, the total number of textbooks used in our analysis is thirty (five publishers times six textbooks used for the whole VHS school system).

\subsection{Analysis process}

We first classify the ways in which RCs are introduced in the textbooks. This gives us the following three categories (examples for each category are illustrated in Table 1):

(1) Explicit instruction focus: Grammatical structures which explicitly introduce RCs to be the main instruction focus of that lesson. Clear and unambiguous RC structures are explicitly presented to learners.

(2) Implicit instruction focus: The main instruction focus of the lesson is on other grammatical structures, which contain or require knowledge of RC formation. Since the main instruction focus is not on RC, teachers may simply present the RC formation to the student and allow the students to assimilate the information in the way that makes the most sense to them.

(3) Examples only: The main instruction focus of the lesson is on other type of grammatical structures which does not contain or require knowledge of RC formation. RCs are presented in the example sentences provided in that lesson.

After the classification, we keep a record of which unit and level of book RC is introduced and also its frequency of appearance. 


\section{Table 1}

Examples for the ways in which RCs are introduced in the textbooks

\begin{tabular}{|c|c|c|c|}
\hline Category & Grammar focus & Structures introduced & Example provided \\
\hline $\begin{array}{l}\text { Explicit instruction } \\
\text { focus }\end{array}$ & $\mathrm{RCs}$ & $\mathrm{S}+\mathrm{V} \ldots$, who/which... & $\begin{array}{l}\text { The sun, which is in the center of } \\
\text { the solar. }\end{array}$ \\
\hline $\begin{array}{l}\text { Implicit instruction } \\
\text { focus }\end{array}$ & Participial phrase & $\mathrm{N}+$ wh-/that (To) N+V-ing/p.p. & $\begin{array}{l}\text { They found a boy who was singing } \\
\text { in the classroom. (To) singing }\end{array}$ \\
\hline Examples only & Passives & $\begin{array}{l}\text { S+be } \\
\text { caught/seen/spotted/heard+V-ing }\end{array}$ & $\begin{array}{l}\text { People who were caught stealing } \\
\text { salt could be imprisoned. }\end{array}$ \\
\hline
\end{tabular}

\section{Results}

\subsection{What types of RCs are introduced in the textbooks?}

Overall, out of twenty types of RCs presented on the difficulty order scale of this study, only eight of them are introduced in the textbooks across the five different publishers. Most of the publishers introduce on average five different types of RCs in the textbooks across the whole three years of schooling. Each of them gives a different focus and emphasis on RCs. Publisher 2 introduces one more type of RC than average while Publisher 5 introduces the least range of RCs to students. Publisher 4 presents various types of RCs most frequently and Publisher 3 presents RCs the least frequently. RCs of indirect object and object of comparison are never introduced to learners at all. As for the genitive RCs, only the genitive of subject is introduced, and it is introduced only by two publishers: Publisher 1 and Publisher 2.

Table 2

Frequency and types of RCs introduced in the textbooks

\begin{tabular}{ccccccccc}
\hline & OS & OO & SS & SO & OOPREP & SOPREP & OSGEN & SSGEN \\
\hline Publisher 1 & 14 & 8 & 10 & 4 & 0 & 0 & 1 & 0 \\
Publisher 2 & 9 & 1 & 7 & 0 & 2 & 0 & 1 & 1 \\
Publisher 3 & 9 & 1 & 2 & 1 & 0 & 1 & 0 & 0 \\
Publisher 4 & 29 & 6 & 18 & 1 & 3 & 0 & 0 & 0 \\
Publisher 5 & 3 & 1 & 8 & 0 & 0 & 0 & 0 & 0 \\
Total & 64 & 17 & 45 & 6 & 5 & 1 & 2 & 1 \\
\hline Note. Ordered left to right in increasing difficulty & & & & & & 0
\end{tabular}

Note. Ordered left to right in increasing difficulty.

Comparing the range and frequency of RCs presented in the textbooks, Publisher 5 appears to put limited emphasis on RCs. It provides not only the least number of different types but also the lowest frequency of RCs in the textbooks. Accordingly, learners using the Publisher 5 textbook version are given the least exposure to RCs, which may put them at a disadvantage in terms of acquisition of RCs formation.

Among those eight types of RCs introduced in the textbooks, OS and SS stand out as the top two types that appear most frequently in the textbooks across all five publishers. Apart from OO, there is a big drop of numbers on the other types of RCs introduced. Even though OO seems to receive a relatively large amount of attention, it is mainly from two publishers, Publisher 1 and Publisher 4.

Note that the top two types of RCs are both relativization of the subject noun phrases, which are claimed to be the most accessible one on the NPAH, and thus the easiest and earliest one to acquire. However, giving the majority of attention to only relativization of the subject noun phrases may result in learners not being aware of or not being familiar with the other various types of RCs that they could encounter in their language use. This is evidenced, for example, in Ammar and Lightbown's (2005) study, suggesting that students need explicit explanation and additional guidance particularly in the formation of the genitive. 
Hua, T.-L.

On top of this, as empirical studies show, learners can benefit from instruction that is focused on lower positions on the NPAH hierarchy (e.g. OPREP) because they are able to generalize the rules or their understanding of RCs to the ones that are on the higher positions (e.g. SU or DO) (e.g. Doughty, 1991; Gass, 1982), but not the other way around (Ortega, 2011). If this is so, it is very likely that, as Pica (2005) pointed out, even though this empirical finding has clear application to teaching practice, it has still not found its way into language curricula yet, or at least not in the current research context.

Table 3

Frequency of RCs in receiving different instruction focus: Explicit instruction focus

\begin{tabular}{rcccccccc}
\hline & OS & OO & SS & SO & OOPREP & SOPREP & OSGEN & SSGEN \\
\hline Publisher 1 & 5 & 8 & 4 & 3 & 0 & 0 & 1 & 0 \\
Publisher 2 & 4 & 1 & 4 & 0 & 2 & 0 & 1 & 1 \\
Publisher 3 & 4 & 1 & 2 & 1 & 0 & 1 & 0 & 0 \\
Publisher 4 & 6 & 3 & 8 & 0 & 2 & 0 & 0 & 0 \\
Publisher 5 & 0 & 0 & 2 & 0 & 0 & 0 & 0 & 0 \\
Total & 19 & 13 & 20 & 4 & 4 & 1 & 2 & 1 \\
\hline
\end{tabular}

Table 4

Implicit instruction focus

\begin{tabular}{ccccccccc}
\hline & OS & OO & SS & SO & OOPREP & SOPREP & OSGEN & SSGEN \\
\hline Publisher 1 & 6 & 0 & 6 & 1 & 0 & 0 & 0 & 0 \\
Publisher 2 & 3 & 0 & 2 & 0 & 0 & 0 & 0 & 0 \\
Publisher 3 & 4 & 0 & 0 & 0 & 0 & 0 & 0 & 0 \\
Publisher 4 & 17 & 2 & 7 & 0 & 1 & 0 & 0 & 0 \\
Publisher 5 & 3 & 1 & 5 & 0 & 0 & 0 & 0 & 0 \\
Total & 33 & 3 & 20 & 1 & 1 & 0 & 0 & 0 \\
\hline
\end{tabular}

Table 5

Examples only

\begin{tabular}{ccccccccc}
\hline & OS & OO & SS & SO & OOPREP & SOPREP & OSGEN & SSGEN \\
\hline Publisher 1 & 3 & 0 & 0 & 0 & 0 & 0 & 0 & 0 \\
Publisher 2 & 2 & 0 & 1 & 0 & 0 & 0 & 0 & 0 \\
Publisher 3 & 1 & 0 & 0 & 0 & 0 & 0 & 0 & 0 \\
Publisher 4 & 6 & 1 & 3 & 1 & 0 & 0 & 0 & 0 \\
Publisher 5 & 0 & 0 & 1 & 0 & 0 & 0 & 0 & 0 \\
Total & 12 & 1 & 5 & 1 & 0 & 0 & 0 & 0 \\
\hline
\end{tabular}

When we look at the introduction of RCs separately from the different degrees of instruction focus they are given, SS and OS remain the top two types of RCs which are frequently presented to students. This is followed by $\mathrm{OO}$, which receives the primary explicit instruction focus from Publisher 1 . The genitive of subject is given explicit instruction focus from Publisher 2 and Publisher 1, with Publisher 2 explicitly introduces genitive subject RCs from both matrix subject and object position while Publisher 1 explicitly introduces it from matrix subject position only. Each type of the genitive RCs is presented to learners only once respectively.

Given that there are various ways of forming RCs (e.g. with regard to which noun phrase position they can relativitize and the function of the RC positions in the matrix sentence), Publisher 5 only explicitly teach one type of RC, SS, which shows that Publisher 5 underrepresents the range of RCs to students in comparison to other textbooks publishers.

It is interesting to note that OS and OO are not explicitly taught to learners using the Publisher 5 textbook version. Instead, they are implicitly taught to learners in conjunction with other grammatical structures. Also, SO from Publisher 4 is only introduced in the examples provided for learning other grammatical structures, and it is 
Textbooks for foreign English language: Do they facilitate students' acquisition of English relative clauses?

never explicitly or implicitly taught to learners. Whereas OS from Publisher 3 first appears in examples but is only later explicitly and implicitly taught to learners. All these different ways of presentation raise an interesting question as to when/if leaners acquire the targeted RCs, e.g. how much information do students elicit from the implicit grammatical instruction focus or through examples only exposure. Are learners able to learn complex forms implicitly or through examples only without explicit instruction?

Language teaching has been debated over the relative merits of explicit and implicit instruction (Williams, 1999). However, a study conducted by Doughty (1991) shows that learners who received either implicit or explicit explanations on RC formation show greater improvement in relativization ability compared to the learners who received exposure only to the RC sentences. Two factors involved that could have certain effect on learners' acquisition from this study are: the degree of explicitness with which leaners' attention is drawn to the features of $\mathrm{RC}$ formation through instruction, and the nature of the instructional materials presented to learners (e.g. perceptual saliency and the frequency of presentation). Therefore, when considering the different ways of grammar presentations in the textbooks, we need to take into account how individual teachers actually present the structure to the students, e.g. the degree of explicitness when teachers introduce the structure and made learners aware of how rules apply to examples.

\subsection{What is the order of RCs introduced in the textbooks?}

\section{Table 6}

First time appearance of RCs in the textbooks and their complexity level

\begin{tabular}{lcccccccc}
\hline & Level 1 & \multicolumn{2}{c}{ Level 2 } & \multicolumn{2}{c}{ Level 3 } & Level 4 & Level 1 & Level 2 \\
\cline { 2 - 8 } & OS & OO & SS & SO & OOPREP & SOPREP & OSGEN & SSGEN \\
\hline Publisher 1 & B2U5 & B2U5 & B2U6 & B2U5 & & & B6U5 & \\
Publisher 2 & B2U1 & B3U2 & B2U4 & & B3U2 & & B3U2 & B3U2 \\
Publisher 3 & B3U5 & B3U5 & B3U5 & B3U8 & & \multirow{2}{*}{ B3U8 } & & \\
Publisher 4 & B1U5 & B1U5 & B1U5 & B5U5 & B1U5 & & & \\
Publisher 5 & B2U8 & B2U8 & B1U2 & & & & & \\
\hline
\end{tabular}

Most of the RCs are introduced in the textbooks at the early stage of students' English learning in VHSs (book level One to Three, which is in the first year and a half of VHSs). Only a very few of RCs are presented at a later stage.

Different types of RCs are mostly introduced at the same time, rather than introduced in a way where increasingly complex types are introduced as learners' progress to the next unit or level. This is particularly the case from Publisher 4. Therefore, even when we look at the unit and level in which RCs are introduced, Publisher 2, Publisher 3, and Publisher 4 appear to respect the order of difficulty, it is arguable whether it truly reflects a consideration of natural difficulty progression.

The complexity level of those RCs introduced in the textbooks is mainly at the easiest level, creating one or two discontinuities. A more complex RCs type: SOPREP, which creates four discontinuities, is only introduced from Publisher 3.

\section{Table 7}

The order of RCs in explicit instruction focus

\begin{tabular}{lcccccccc}
\hline & Level 1 & \multicolumn{2}{c}{ Level 2 } & \multicolumn{2}{c}{ Level 3 } & Level 4 & Level 1 & Level 2 \\
\cline { 2 - 8 } & OS & OO & SS & SO & OOPREP & SOPREP & OSGEN & SSGEN \\
\hline Publisher 1 & B2U5 & B2U5 & B2U7 & B2U5 & & & B6U5 & \\
Publisher 2 & B4U1 & B3U2 & B3U2 & & B3U2 & & B3U2 & B3U2 \\
Publisher 3 & B3U5 & B3U5 & B3U5 & B3U8 & & B3U8 & & \\
Publisher 4 & B1U5 & B1U5 & B1U5 & & B1U5 & & & \\
Publisher 5 & & & B1U2 & & & & & \\
\hline
\end{tabular}


Hua, T.-L.

Table 8

The order of RCs in implicit instruction focus

\begin{tabular}{|c|c|c|c|c|c|c|c|c|}
\hline & \multirow{2}{*}{$\frac{\text { Level } 1}{\text { OS }}$} & \multicolumn{2}{|c|}{ Level 2} & \multicolumn{2}{|c|}{ Level 3} & \multirow{2}{*}{$\begin{array}{c}\text { Level } 4 \\
\text { SOPREP }\end{array}$} & \multirow{2}{*}{$\begin{array}{l}\text { Level } 1 \\
\text { OSGEN }\end{array}$} & \multirow{2}{*}{$\begin{array}{l}\text { Level } 2 \\
\text { SSGEN }\end{array}$} \\
\hline & & $\mathrm{OO}$ & SS & SO & OOPREP & & & \\
\hline Publisher 1 & B2U6 & & B2U6 & B4U2 & & & & \\
\hline Publisher 2 & B2U1 & & B2U4 & & & & & \\
\hline Publisher 3 & B3U5 & & & & & & & \\
\hline Publisher 4 & B2U8 & B2U8 & B5U1 & & B2U8 & & & \\
\hline Publisher 5 & B2U8 & B2U8 & B1U8 & & & & & \\
\hline
\end{tabular}

Table 9

The order of RCs in examples only

\begin{tabular}{|c|c|c|c|c|c|c|c|c|}
\hline & Level 1 & \multicolumn{2}{|c|}{ Level 2} & \multicolumn{2}{|c|}{ Level 3} & \multirow{2}{*}{$\begin{array}{c}\text { Level } 4 \\
\text { SOPREP }\end{array}$} & \multirow{2}{*}{$\begin{array}{l}\text { Level } 1 \\
\text { OSGEN }\end{array}$} & \multirow{2}{*}{$\begin{array}{l}\text { Level } 2 \\
\text { SSGEN }\end{array}$} \\
\hline & $\mathrm{OS}$ & $\mathrm{OO}$ & SS & $\mathrm{SO}$ & OOPREP & & & \\
\hline Publisher 1 & B3U6 & & & & & & & \\
\hline Publisher 2 & B3U4 & & B3U7 & & & & & \\
\hline Publisher 3 & B2U5 & & & & & & & \\
\hline Publisher 4 & B4U1 & B5U5 & B4U4 & B5U5 & & & & \\
\hline Publisher 5 & & & B3U5 & & & & & \\
\hline
\end{tabular}

When we look at the explicit instruction focus, Publisher 2 seems to be no longer in line with the order of difficulty as OS is explicitly introduced later than other more complex RCs types. However, when we look at the table of implicit instruction focus, OS is implicitly introduced at an earlier stage (Book Two Unit One). This means that OS is introduced to learners earlier than other more complex RC type, but only implicitly. SS is also implicitly introduced to learners before it is explicitly introduced. A similar situation is also found in Publisher 3, where OS is presented in example sentences before it is implicitly or explicitly introduced. This raises an interesting question of the effect of different timing in different ways of presenting RCs to learners.

\section{Discussion}

The examination of the RCs introduced in the textbooks reveals the following two aspects:

Firstly, teaching does not reflect the full variety of RCs, and the focus seems to be concentrated on only a few types of RC. The majority of instruction focus is given to relativization of the subject noun phrases (OO \& SS), while the other types of RCs are either not taught at all or are given the least emphasis. However, as mentioned earlier, research has pointed out that certain types of RCs, e.g. the genitive, require additional instruction guidance; otherwise, learners would not be able to correctly form the genitive RCs (Ammar \& Lightbown, 2005).

Empirical research has also shown that in reference to NPAH, learners are able to generalize instruction on more marked RCs to the less marked structures (Gass, 1982; Eckman, Bell, \& Nelson, 1988). In this case, a more efficacious model for syllabus design would be one in which a more difficult structure preceded an easier one (Gass, 1982), which apparently is not the case for the textbooks under examination in the current study. However, it should be borne in mind that it has been argued that the evidence for unidirectional generalizability is not conclusive, and further research is needed to determine the directionality of generalization (Hamilton, 1994).

Secondly, in several cases, the introduction of RCs in the textbooks does not reflect the natural difficulty progression for RC acquisition. The difficulty orders for English relativization manifest developmental sequences and the degree of difficulty posed to the learner in acquiring different complexity levels of RCs. However, most of the RCs are presented to learners at the same time in the textbooks. This contradicts leaners' natural orderings and may result in inhibition of the learning process (Gass, 1982). As Bao (2015) has pointed 
Textbooks for foreign English language: Do they facilitate students' acquisition of English relative clauses?

out, a majority of learners are inclined to avoid relative clauses use at the outset because it is difficult for them. Therefore, the learning process is further inhibited.

\section{Conclusions}

While there are a wide range of international, national, regional, and in-house textbooks available for the teaching and learning of a foreign English language, they are very likely be complied without an insight from the order of grammatical structure difficulty of SLA. In light of available empirical evidence and well-established hypotheses of the difficulty order for RC acquisition, this study applied the notion of processing discontinuity to create difficulty orders for English relativization, and examined if current EFL textbooks used in vocational high schools in Taiwan facilitate students' acquisition of English relative clauses. The findings of this study can potentially shed light as one evidence-based source of information on the textbook development practices in other EFL contexts worldwide. The examination of RC types and sequencing can assist in ensuring that the natural acquisition processes are considered in students' grammatical development. In this way, classroom practices can better serve to promote language development rather than limiting it through intuitive-but not always accurate-practice. This study also has implications for affecting the intuitive approach textbook writers often take to their grammatical structure sequencing, as well as how the classroom teacher's strict adherence to such textbooks can result in students' avoidance of relative clause use, thus limiting their language development. Curriculum designers and other educators can be more fully informed about inherent grammatical complexity. This can better guide them in textbook choices and in sequencing grammatical structures in their syllabi.

Acknowledgements: The author would like to express her fullest gratitude to Professor Detmar Meurers, from the Department of Linguistics of the University of Tübingen, for his helpful advice and feedback on this study.

Funding: This research was funded by the LEAD Graduate School, University of Tübingen, under the project of the Excellence Initiative of the German federal and state governments under project number: 19110517.

\section{References}

Ammar, A., \& Lightbown, P. M. (2005). Teaching marked linguistic structures-more about the acquisition of relative clauses by Arab learners of English. In A. Housen \& M. Pierrard (Eds.), Investigations in instructed second language acquisition (pp. 167-198). Berlin-New York: Mouton de Gruyter.

Bao, X. (2015). An investigation of sources of errors in the use of relative clauses by English majors. English Language and Literature Studies, 5(3), 37-145. https://doi.org/10.5539/ells.v5n3p137

Chang, J. (2001). Chinese speakers. In M. Swan \& B. Smith (Eds.), Learner English: A teacher's guide to interference and other problems (pp. 310-324). Cambridge: Cambridge University Press. https://doi.org/10.1017/CBO9780511667121.022

Cho, D. W., \& Lee, K. (2016). English relative clauses in science and engineering journal papers: A comparative corpus-based study for pedagogical purposes. Ampersand, 3, 61-70. https://doi.org/10.1016/j.amper.2016.03.002

Cook, V. (2009). Developing links between second language acquisition research and language teaching. In K. Knapp \& B. Seidlhofer (Eds.), Handbooks of foreign language communication and learning (pp. 139-162). Berlin ; New York : Mouton de Gruyter.

Doughty, C. (1991). Second language instruction does make a difference. Studies in second language acquisition, 13, 431-469. https://doi.org/10.1017/S0272263100010287

Eckman, F., Bell, L., \& Nelson, D. (1988). On the generalization of relative clause, instruction in the acquisition of English as Second Language. Milwaukee: University of Wisconsin. https://doi.org/10.1093/applin/9.1.1

Ellis, R. (2005). Principles of instructed language learning. System, 33(2), 209-224. 
Hua, T.-L.

https://doi.org/10.1016/j.system.2004.12.006

Ellis, R. (2006). Current issues in the teaching of grammar: An SLA perspective. TESOL Quarterly, 40(1), 83-107. https://doi.org/10.2307/40264512

Everington, K. (2018). English vocabulary requirement in Taiwan high schools reduced by 2,500 words. Taiwan News. Retrieved from https://www.taiwannews.com.tw/en/news/3347797

Felix, S. W. (1981). The effect of formal instruction on second language acquisition. Language Learning, 31(1), 87-112. https://doi.org/10.1111/j.1467-1770.1981.tb01374.x

Gass, S. (1979). Language transfer and universal grammatical relations. Language Learning, 29(2), 327-344. https://doi.org/10.1111/j.1467-1770.1979.tb01073.x

Gass, S. M. (1982). From theory to practice. In M. Hines \& W. Rutherford (Eds.), On TESOL '81: Selected papers from the Fifteenth Annual Conference of Teachers of English to Speakers of Other Languages (pp. 129-139). Washington DC: TESOL.

Hamilton, R. L. (1994). Is implicational generalization unidirectional and maximal? Evidence from relativization instruction in a second language. Language Learning, 44(1), 123-157. https://doi.org/10.1111/j.1467-1770.1994.tb01451.x

Hansen-Strain, L., \& Strain, J. (1989). Variation in the relative clause of Japanese learners. JALT Journal, 11(2), 211-237.

Hyltenstam, K. (1984). The use of typological markedness conditions as predictors in second language acquisition: The case of pronominal copies in relative clauses. In R. Anderson (Ed.), Second languages: A crosslinguistic perspective (pp. 39-60). Rowley, MA: Newbury House.

Ishihara, N., \& Cohen, A. D. (2014). Teaching and learning pragmatics: Where language and culture meet. London and New York: Routledge. https://doi.org/10.4324/9781315833842

Izumi, S. (2003). Processing difficulty in comprehension and production of relative clauses by learners of English as a second language. Language Learning, 53(2), 285-323. https://doi.org/10.1111/1467-9922.00218

Keenan, E. L., \& Comrie, B. (1977). Noun phrase accessibility and universal grammar. Linguistic Inquiry, 8(1), 63-99.

Keßler, J.-U. (2008). Processability approaches to second language development and second language learning. Newcastle, UK: Cambridge Scholars Publishing.

Kuno, S. (1974). The position of relative clauses and conjunctions. Linguistic Inquiry, 5, 117-136.

Mansouri, F., \& Duffy, L. (2005). The pedagogic effectiveness of developmental readiness in ESL grammar instruction. Australian Review of Applied Linguistics, 28(1), 81-99. https://doi.org/10.1075/aral.28.1.06man

Ministry of Education. (2013). Proved textbook lists. Retrieved from http://learn.pmes.tyc.edu.tw/book95/ListBook.asp

Ortega, L. (2011). Sequences and processes in language learning. In M. H. Long \& C. J. Doughty (Eds.). The handbook of language teaching (pp.81-105). West Sussex, UK: Blackwell Publishing Ltd. https://doi.org/10.1002/9781444315783.ch6

Pavesi, M. (1986). Markedness, discoursal modes and relative clause formation in a formal and informal context. Studies in Second Language Acquisition, 8, 38-55. https://doi.org/10.1017/S0272263100005829

Pica, T. (2005). Second language acquisition research and applied linguistics. In E. Hinkel (Ed.), Handbook of second language teaching and learning (pp. 263-280). New Jersey: Lawrence Erlbaum Associates, Inc.

Pienemann, M. (1984). Psychological constraints on the teachability of languages. Studies in Second Language Acquisition, 6(2), 186-214.

Pienemann, M. (1998). Language processing and second language development: Processability theory. Amsterdam \& Philadelphia: John Benjamins. https://doi.org/10.1075/sibil.15

Williams, J. (1999). Memory, attention and inductive learning. Studies in Second Language Acquisition, 21, 1-48. https://doi.org/10.1017/S0272263199001011

Wolfe-Quintero, K. (1992). Learnability and the acquisition of extraction in relative clause and wh-questions. Studies in Second Language Acquisition, 14, 39-70. https://doi.org/10.1017/S0272263100010469 


\section{Appendix A}

Degrees of discontinuity to the various types of RCs in reference to the NPAH

\begin{tabular}{|c|c|c|}
\hline RC type & Example sentences & No. of discontinuities \\
\hline S S & $\begin{array}{l}\text { The man who }{ }_{i}\left[s t_{i} \text { wrote the }\right. \\
\text { book ] is my friend. }\end{array}$ & 2 \\
\hline $\mathrm{SO}$ & $\begin{array}{l}\text { The strong determination that } i \\
\left.\left[\mathrm{~s} \text { the runners [ vP showed } \mathrm{t}_{\mathrm{i}}\right]\right] \\
\text { moved me to tears. }\end{array}$ & 3 \\
\hline S IO & $\begin{array}{l}\text { The man who }{ }_{i}[\mathrm{~s} \text { we [vp gave } \\
\left.\left.\text { the wallet }\left[\mathrm{pp}_{\mathrm{p}} \mathrm{t}_{\mathrm{i}}\right]\right]\right] \text { is a police. }\end{array}$ & 4 \\
\hline S OPREP & $\begin{array}{l}\text { The man who }{ }_{i}[\mathrm{~s} \text { we [vp read } \\
\left.\left.\left[\mathrm{pp} \text { about } \mathrm{t}_{\mathrm{i}}\right]\right]\right] \text { is here. }\end{array}$ & 4 \\
\hline S OCOMP & $\begin{array}{l}\text { The man who }{ }_{i}[\mathrm{~s} \text { she [ vP is } \\
\left.\left.\left.\text { taller [ } \mathrm{cp} \text { than }\left[\mathrm{s} \mathrm{t}_{\mathrm{i}}[\mathrm{vP} \mathrm{e}]\right]\right]\right]\right] \text { is my } \\
\text { brother. }\end{array}$ & 6 \\
\hline $\mathrm{OS}$ & $\begin{array}{l}\text { Cinderella is the girl who }{ }_{i}\left[\mathrm{~s}_{\mathrm{i}}\right. \\
\text { wore the shoes to the party]. }\end{array}$ & 1 \\
\hline $\mathrm{OO}$ & $\begin{array}{l}\text { The prince brought the shoes } \\
\text { which }_{\mathrm{i}}\left[\mathrm{s}_{\mathrm{s}} \text { Cindrella [ vP wore } \mathrm{t}_{\mathrm{i}}\right. \\
\text { to the party last night]]. }\end{array}$ & 2 \\
\hline $\mathrm{O}$ IO & $\begin{array}{l}\text { He does not know the man that }{ }_{i} \\
{\left[\mathrm{~s} \text { we [ vp gave the wallet }\left[_{\mathrm{pp}} \text { to }\right.\right.} \\
\text { ti }]] \text { ] yesterday. }\end{array}$ & 3 \\
\hline O OPREP & $\begin{array}{l}\text { I saw the man who }{ }_{i}[\mathrm{~s} \text { we }[\mathrm{vP} \\
\left.\left.\operatorname{read}\left[\mathrm{pp}_{\text {about }} \mathrm{t}_{\mathrm{i}}\right]\right]\right]\end{array}$ & 3 \\
\hline O OCOMP & $\begin{array}{l}\text { I know the man who }{ }_{\mathrm{i}}[\mathrm{s} \text { she }[\mathrm{vP} \\
\left.\left.\text { is taller }\left[\mathrm{cp} \text { than }\left[\mathrm{s}_{\mathrm{i}}[\mathrm{VP}]\right]\right]\right]\right] \text {. }\end{array}$ & 5 \\
\hline
\end{tabular}


Hua, T.-L.

\section{Appendix B}

Degrees of discontinuity to the genitive types of RCs

\begin{tabular}{|c|c|c|}
\hline RC type & Example sentences & No. of discontinuities \\
\hline S S GEN & $\begin{array}{l}\left.\text { The man }{ }_{i} \text { [whose }{ }_{i} \text { wife }\right]_{j}\left[s t_{j}\right. \\
\text { came ] is a police. }\end{array}$ & 2 \\
\hline S O GEN & $\begin{array}{l}\left.\text { The man }_{i} \text { [whose }_{i} \text { wife }\right]_{j}[\mathrm{~s} I \\
{\left[\mathrm{vP}_{\mathrm{Saw}} \mathrm{t}_{\mathrm{j}}\right] \text { is a police. }}\end{array}$ & 3 \\
\hline S IO GEN & $\begin{array}{l}\text { The man }{ }_{i}\left[\text { whose }_{i} \text { wife }\right]_{j}\left[\mathrm{~s}_{\mathrm{I}}\right. \\
\left.\left[\text { vp gave the book }\left[{ }_{p p} \text { to } t_{j}\right]\right]\right] \text { is } \\
\text { a police. }\end{array}$ & 4 \\
\hline S OPREP GEN & $\begin{array}{l}\text { The man }{ }_{i}\left[\text { whose }_{i} \text { wife }\right]_{j}[s \mathrm{I} \\
{\left[\text { vp looked [ } \text { pp }_{\mathrm{j}} \text { at } \mathrm{t}_{\mathrm{j}} \text { is a }\right.} \\
\text { police. }\end{array}$ & 4 \\
\hline S OCOMP GEN & $\begin{array}{l}\text { The man }{ }_{i}\left[\text { whose }_{i} \text { wife }\right]_{j}[\mathrm{~s} \text { I } \\
{\left[\mathrm{vP} \text { am older [ } \mathrm{cp}_{\mathrm{p}} \text { than }\left[\mathrm{s} \mathrm{t}_{\mathrm{j}}[\mathrm{vP}\right.\right.} \\
\mathrm{e}]]]]] \text { is a police. }\end{array}$ & 6 \\
\hline O S GEN & $\begin{array}{l}\text { I know the man } \text { [whose }_{i} \text { wife }_{j} \\
{\left[s t_{j} \text { is a teacher]. }\right.}\end{array}$ & 1 \\
\hline O O GEN & $\begin{array}{l}\left.\text { I know the man }_{i} \text { [whose }_{i} \text { wife }\right]_{j} \\
{\left[{ }_{s} I\left[\text { vP } \text { like }_{j}\right]\right] \text {. }}\end{array}$ & 2 \\
\hline O IO GEN & $\begin{array}{l}\text { I know the man }{ }_{i}\left[\text { whose }_{i} \text { wife }\right] \\
\mathrm{j}_{\text {[ }} \mathrm{s} \text { I [vp gave the book [ }{ }_{\mathrm{pp}} \text { to } \\
\left.\left.\left.\mathrm{t}_{\mathrm{j}}\right]\right]\right]\end{array}$ & 3 \\
\hline O OPREP GEN & 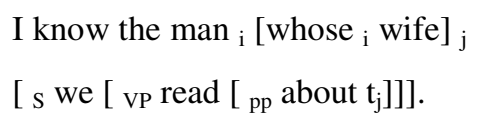 & 3 \\
\hline O OCOMP GEN & $\begin{array}{l}\text { I know the man }{ }_{i}\left[\text { whose }_{i} \text { wife }\right]_{j} \\
{\left[{ }_{s} \text { She }\left[v P \text { is taller }\left[\mathrm{cp} \text { than }\left[\mathrm{s} \mathrm{t}_{\mathrm{j}}\right.\right.\right.\right.} \\
[\mathrm{vP}]]]]]\end{array}$ & 5 \\
\hline
\end{tabular}

